\title{
Challenges in the Calculation of Residual Stresses in Thick-walled Components
}

\author{
Jakob Klassen ${ }^{1, a^{*}}$, Thomas Nitschke-Pagel ${ }^{1, b}$ and Klaus Dilger ${ }^{1, \mathrm{c}}$ \\ ${ }^{1}$ Langer Kamp 8, 38106 Braunschweig, Germany \\ aj.klassen@tu-braunschweig.de, bt.pagel@tu-braunschweig.de, ck.dilger@tu-braunschweig.de
}

\section{Keywords: Residual Stresses, Numerical Welding Simulation, Multi-Layer Welds}

\begin{abstract}
Numerical simulations of welding induced residual stresses and distortion is still a challenging task, especially with regard to thick-walled structures. These structures are mostly welded with high numbers of layers. Usually adjacent welds influence each other. Therefore, simple 2D calculations become unsuitable, thus, leading to the necessity of $3 \mathrm{D}$ transient calculations. In turn 3D multi-layer welding simulations require large finite element models. To account for steep temperature gradients in the weld and the heat affected zone each layer has to be modeled using rather fine elements. Thus, numerical models become very large regarding the degrees of freedom. Significant simplifications are common practice, although it is known that these might cause inaccurate or even wrong results. The current paper presents 3D transient finite element simulations of welding residual stresses and distortions in multi-layer welds of $29 \mathrm{~mm}$ thick-walled components of a construction steel grade S355N. Furthermore, several modelling simplification approaches were applied. During welding temperature profiles were recorded to validate numerical models. After each layer residual stress measurements were carried out by means of X-ray diffraction (XRD). Furthermore, some weld fill levels were investigated by neutron diffraction (ND). This allowed the comparison of real through-thickness residual stress distributions with numerical simulations.
\end{abstract}

\section{Introduction}

Residual stresses are known to influence fatigue strength of welded components. Especially welding residual stresses in site joints of larger structures are of interest already in design state. However, these stresses are hard to determine. One of the reasons can be seen in difficulties of accessibility and another one in the lack of measuring equipment availability. And even if one is able to measure residual stresses in the areas of interest, which are in the weld itself or in the heat affected zone, those measurements are limited to the near surface residual stresses. Through thickness residual stress states remain unknown. As numerical welding simulations are not limited to those kinds of restrictions, designers of welded structures are interested in using FEM for residual stress calculations since the beginning of the last century, e.g. [1]. However, numerical simulations of welding induced residual stresses and distortion is still a challenging task, especially with regard to thick-walled structures. These structures are mostly welded with high numbers of layers. Furthermore, adjacent welds influence each other and make a simple 2D calculation unsuitable by means of calculated result quality, thus leading to the necessity of $3 \mathrm{D}$ transient calculations. However, 3D multi-layer welding simulations require large finite element models with rather fine geometric discretization to account for steep temperature gradients in the weld and the heat affected zones. Thus, numerical models become very large by means of degrees of freedom. These large numerical models again result in high computational times. To reduce calculation times simplifications are common practice. Examples of which are thermal cycles (TC) instead of transient calculations or lumping several weld beads to larger layers. However, these simplifications cannot be verified through experimental testing. Nevertheless, these approaches are often used although it is known that simplified calculations of residual stresses might cause inaccurate or even wrong results. 
As stated above, one example for simplifications in numerical simulations of multi-layer welding is the lumping technique. This technique has been often applied to 2D modelling [2], [3]. Although it is often enough stated that its application on 3D would not be easy [4], lumping still is sometimes applied to 3D multi-layer welding. It is noted here that numerical modelling is somewhat different for distortion and residual stress calculations. Some approaches lead to accurate distortions while residual stresses do not agree with measured results.

The presented paper intends to show some results of an ongoing research project. The focus of this research is to investigate feasibility of lumping technique on transient $3 \mathrm{D}$ numerical residual stress simulations. A $29 \mathrm{~mm}$ thick-walled specimen of a general construction steel (German steel grade S355) with a $\mathrm{V}$-groove was welded in experimental investigations. Welding experiments were accompanied by temperature measurements and layer-wise residual stress determinations by means of X-ray diffraction. Furthermore, measurements were carried out at the E3 instrument at HelmholtzZentrum Berlin using neutron diffraction for through-thickness residual stress state determination. These measurements were needed for validating numerical models and to verify calculated results.

The comparison between the full numerical models and the experiment reveals close agreement. However, comparison of the full numerical model with simplified approaches showed partially rather large discrepancies, although temperature profiles used for validation were comparable. At this state of the work it can be concluded that lumping is applicable to multi-layer welds by means of calculated distortions. However, caution must be used when applying this technique on numerical residual stress simulations.

\section{Experimental set-up}

Welding experiments were carried out on several butt welded $29 \mathrm{~mm}$ thick steel plates with a Vgroove (see Fig. 1). The overall specimen's dimensions were $350 \mathrm{~mm}$ x $350 \mathrm{~mm}$ x $29 \mathrm{~mm}$. Welding parameters (current, voltage, wire feed and travel speed) were set equal for each weld bead. This simply allows variations of weld build-up in numerical modelling and keeping energy input in balance.
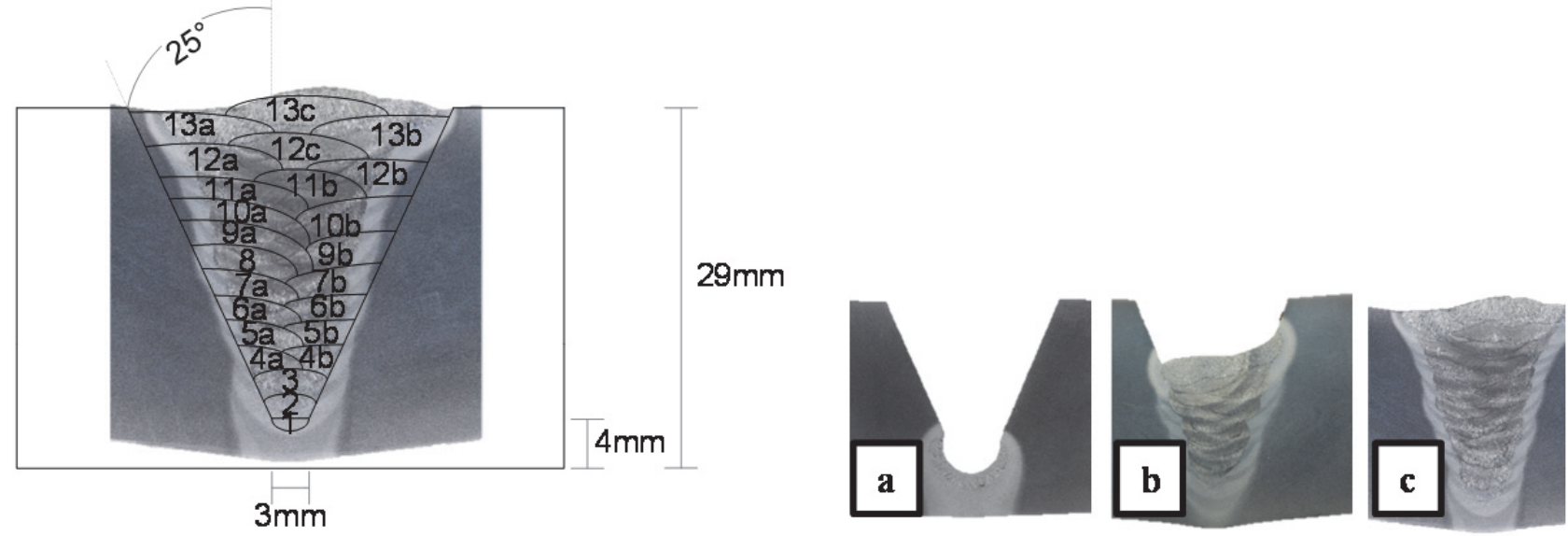

Fig. 1: Macrosection of the specimen after final passes and weld geometry from the welding procedure specification including weld bead numbering

Fig. 2: Macrosections of different weld fill levels. After root pass (a), half weld fill level (b), after final capping passes (c)

Macrosections were taken after each pass for most precise in layers modelling (Fig. 2). Furthermore, each weld pass was followed by displacement measurements (compare Fig. 4) as well as near surface residual stress determinations by means of X-ray diffraction (XRD) (compare Fig. 3). Diffraction lines (\{211\}-patterns) were obtained with $\mathrm{CrK} \alpha$-radiation using a $2 \mathrm{~mm}$ collimator. 
Afterwards residual stresses were calculated with the $\sin ^{2} \psi$-method as described in [5]. Through thickness residual stress measurements by means of neutron diffraction (ND) were carried out at the E3 instrument at Helmholtz-Zentrum Berlin. Since beam time is limited and specimen's thickness require high measuring times, only two different weld fill levels were measured so far (b and $\mathrm{c}$ in Fig. 2).

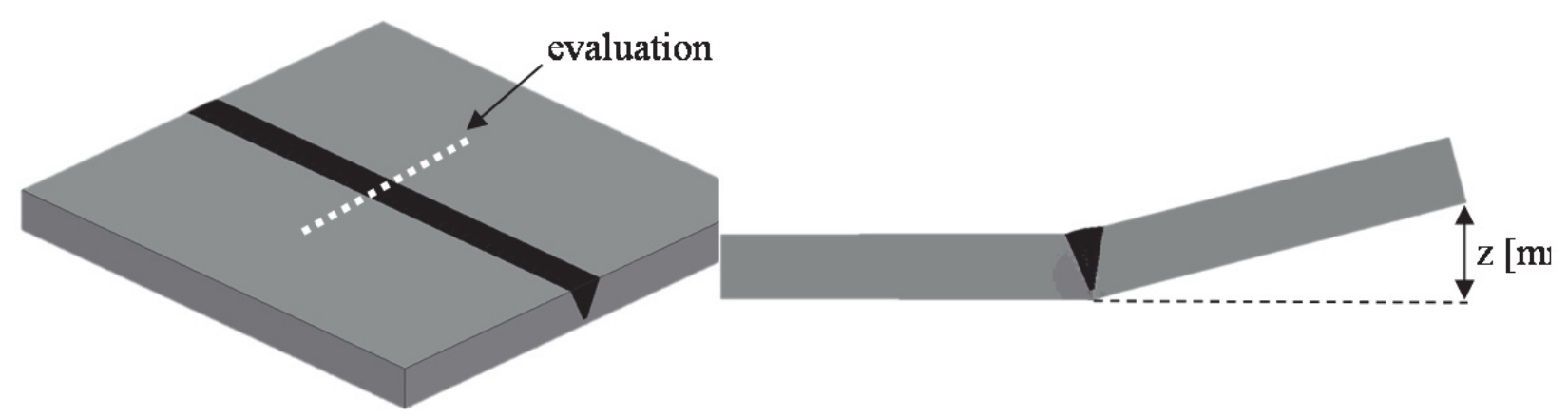

Fig. 3: Measuring and evaluation path for $X R D$ and FEM

Fig. 4: Measuring location for out of plane distortion

\section{Numerical welding simulations}

Finite element analyses (FEA) were carried out using the commercially available welding simulation software SYSWELD. Phase transformation as well as temperature-dependent plasticity was taken into account. Material data was taken from software's data base. This data have been used before and have shown satisfactory results. However, the aim of this work was to investigate relative differences in calculated results through modelling variations. Therefore, not much effort was put into generating steel batch dependent material data.

In addition to the fully transient 3D simulations based on experimentally obtained data two simplifications were carried out, which are lumping several weld beads to larger layers as well as applied thermal cycle technique (TC). In the latter transient and therefore time consuming calculations are avoided. Instead, a temperature profile is imposed on all elements of one bead at the same time. Thus, influences of transient effects (e.g. heat transfer or gap opening in front of flux) remain unconsidered. Each numerical model and its FE mesh are shown in Fig. 5. This part of the investigation has been carried out on a numerically basis only, using a model of half the length to save calculation times.
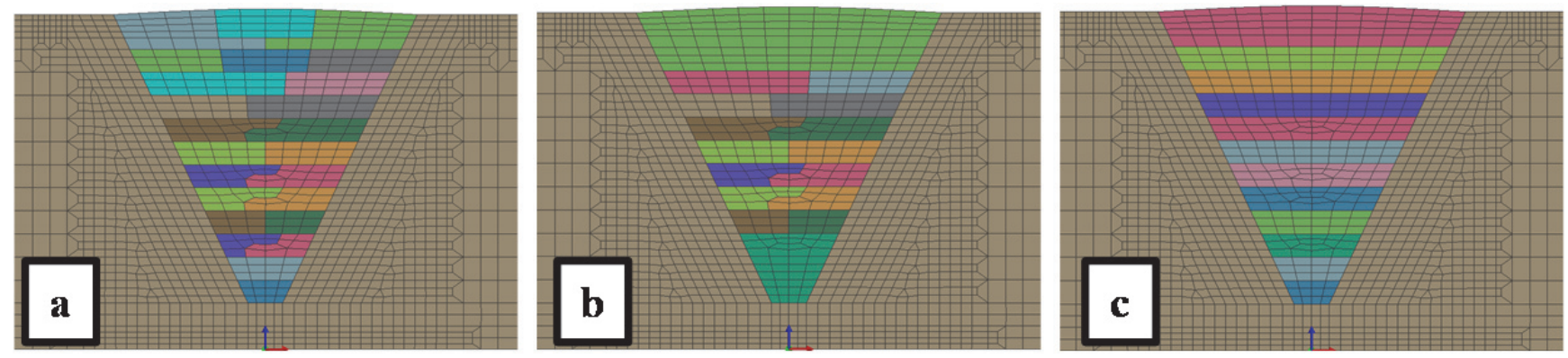

Fig. 5: Weld build-up and FE mesh in numerical models. Fully transient model with moving heat source and thermal cycle approach model based on macrosections from experiments (a); simplified by means of lumping the first and the last three layers (b); simplified by means of lumping in layers (c) 


\section{Results}

Fully transient calculations with moving heat sources are time consuming. Still, these calculations were done first to validate the numerical model by means of defined boundary conditions and used material data etc.. As can be seen in the following (Fig. 6 through Fig. 9) results of numerical welding simulation and experiments correspond well. Slight deviations as in Fig. 7 can be explained by geometrical imperfections and discrepancies in some material data. Latter was set equal for weld and parent material for simplification reasons. Even through-thickness residual stresses and out of plane distortions correspond well. Standard deviation of measured results was $\pm 30 \mathrm{MPa}$ at maximum. However, standard deviations are not shown in diagrams for clarity reasons.

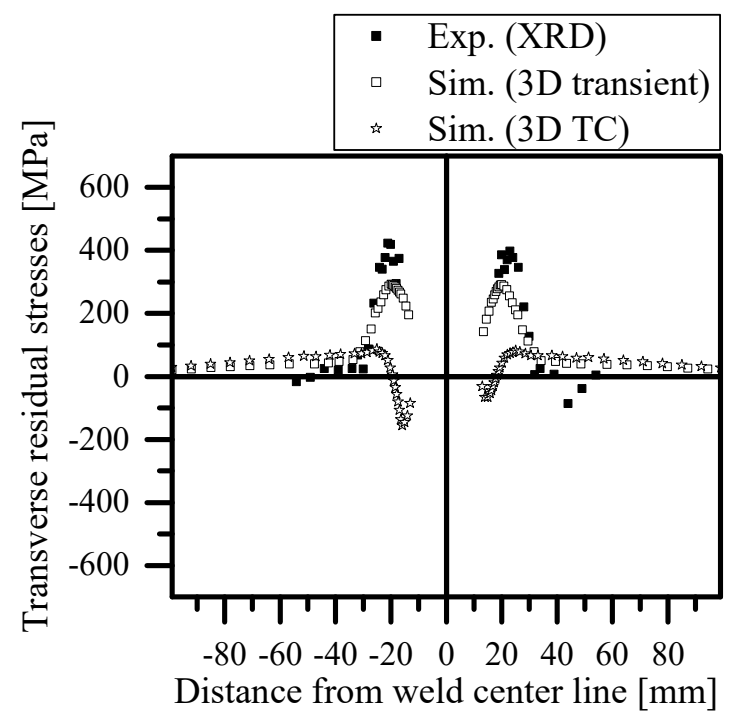

Fig. 6: Comparison of transverse residual stresses on top surface perpendicular to the weld in the middle of the specimen

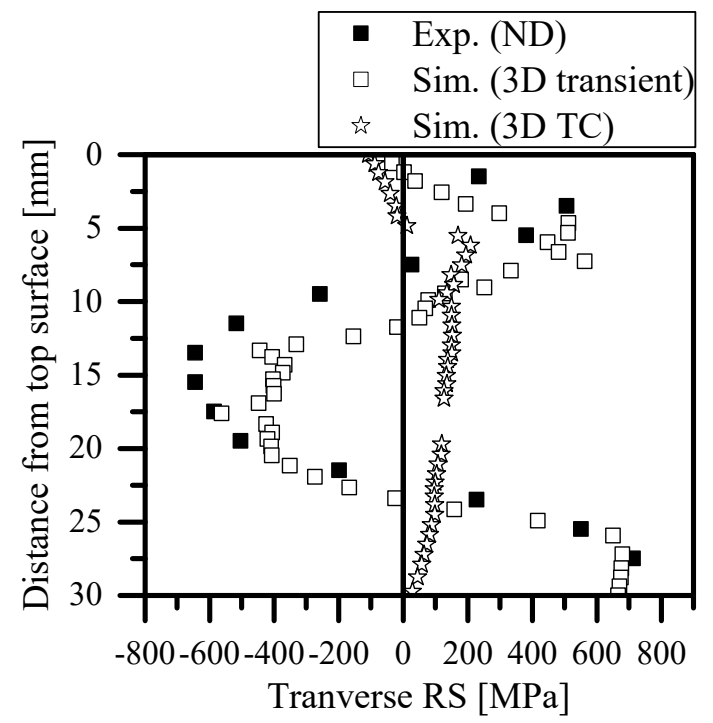

Fig. 8: Comparison of calculated and measured through-thickness residual stresses in transverse direction in the middle of the weld.

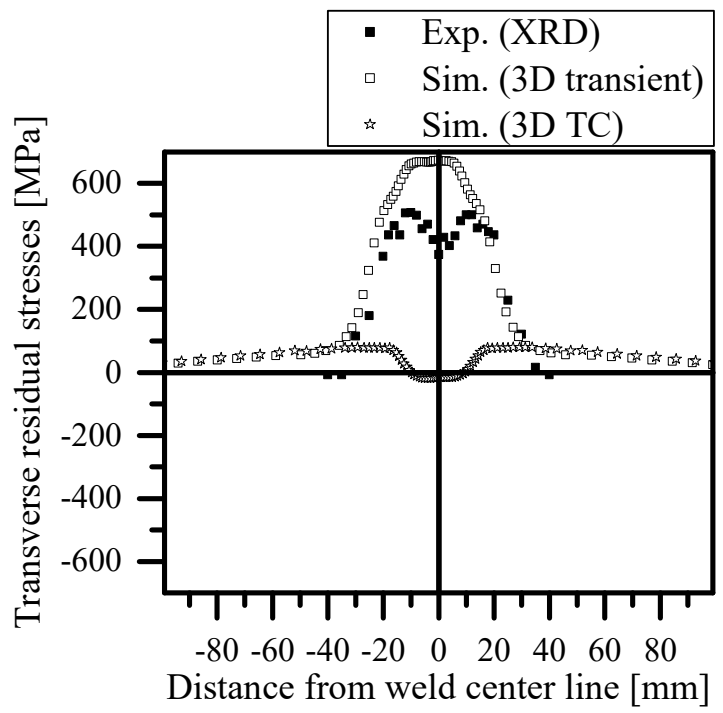

Fig. 7: Comparison of transverse residual stresses on bottom surface perpendicular to the weld in the middle of the specimen

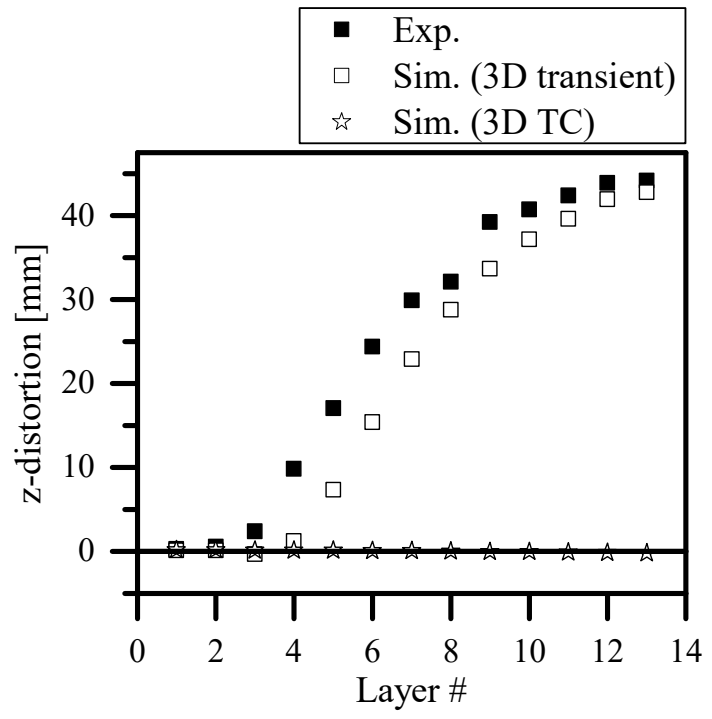

Fig. 9: Comparison of calculated and measured out of plane deformation 
The applied thermal cycle approach (TC) is not suitable for simplifying this numerical model. Although there is a significant reduction in CPU hours, the results are not trustworthy. Neither by means of residual stresses nor calculated displacement, not even in direction. Similar findings were published by [6] and explained by significant differences in heat input and accumulated shrinking.

Further simplification approaches were investigated with smaller models and on numerical basis only. One reason for this is the limitation in actual welding processes regarding energy input and therefore a lack in experimentally obtainable data for validation. Another reason is calculation times. Since it should be sufficient to compare qualitative differences in applied simplifications, smaller models were set up for this purpose.

Results of applied lumping compared with fully transient calculations are shown in the following figures. As can be seen in Fig. 10 the out of plane deformation is comparable for lumping the first and last layers. Increasing lumping for all beads of each layer led to strong deviations. However, through-thickness residual stresses in transverse direction to the weld show significant discrepancy (Fig. 11) in sign and quantitative values for each model. The same applies to residual stresses in other directions as well as the calculated phase proportions (not shown here).

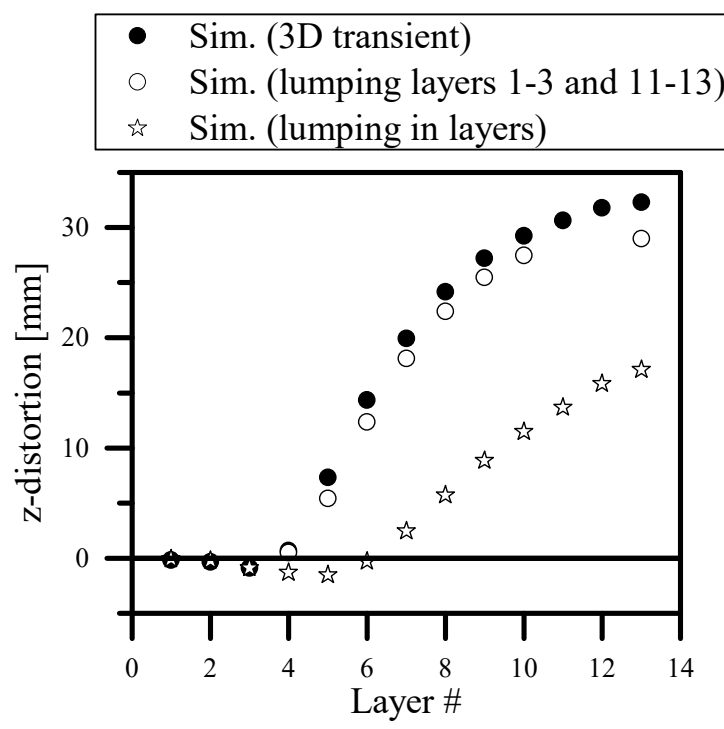

Fig. 10: Comparison of calculated out of plane deformation in fully transient model and models with applied lumping

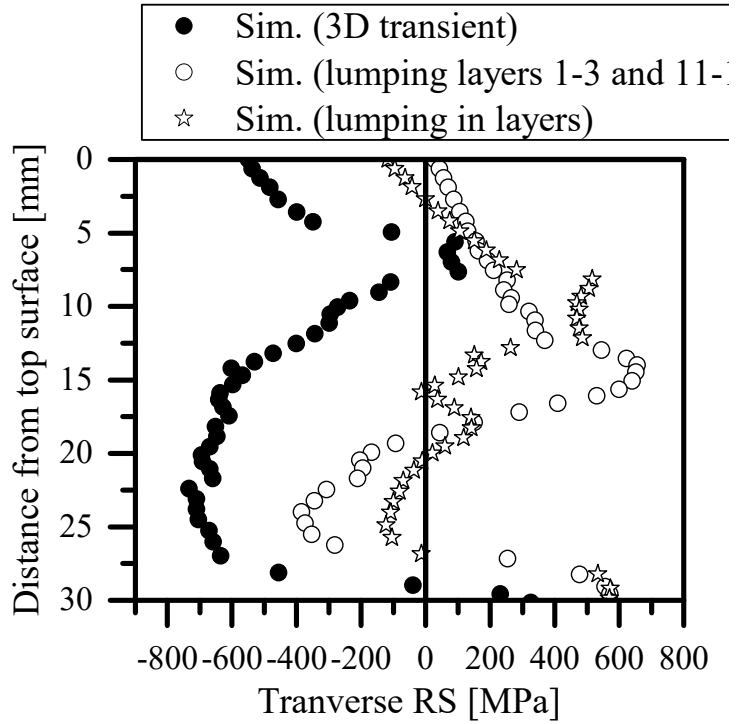

Fig. 11: Comparison of calculated throughthickness transverse residual stresses in the middle of the weld in fully transient model and models with applied lumping

\section{Discussion}

It was shown that residual stresses may be calculated correctly even for multi-pass welds. However, it is noted that fully transient welding simulations with moving heat sources are needed for accurate prediction of residual stress distributions. Similar findings based on other numerical simplification approaches were published by [7]. Furthermore, it can be found in literature that simplifications by means of lumping or applying thermal cycles is sufficient for predicting welding induced distortion. This, however, has to be strictly limited to validated models and never should be expanded on or mistaken for residual stress calculations.

Although reasons for false results through different simplification approaches are evident, they still are tempting and used rather often. On the one hand, experimental data for validation is hard and costly to obtain. On the other hand, these data is not even needed if simplifications are applied, since it is just not possible to weld in real life as it is in finite element analyses. 
It is noted that presented approaches were limited to the same energy input over all states. Energy balance was to keep as a premise. It may be possible to adjust energy input or weld pool geometry in simplified numerical modeling to reach higher precision levels. However, this would not only mean a large number of iteration steps, but also would be a trial and error approach. This, however, is not an expedient task. If welding simulation is to be used in industrial practice, numerical engineers will have to deal with data from their shops or welders on site. And these data will mostly be limited to current, voltage and torch travel speed. Therefore, the overall aim of numerical welding simulation should be providing solutions not only fast but also based on very little data.

\section{Acknowledgement}

We thank HZB for the allocation of neutron radiation beam time. Special thanks to Dr. Boin for his support during beam time at HZB. We also thank Ms. Lepper for her contribution to numerical modelling.

\section{References}

[1] G. Bierett, „Versuche zur Ermittlung der Schrumpfspannungen in geschweißten Stumpfnahtverbindungen, “VDI Zeitschrift des Vereins Deutscher Ingenieure, Bd. 78, pp. 709$715,1934$.

[2] Y. Ueda, K. Iida, M. Saito und A. Okamoto, „Finite Element Modeling and Residual Stress Calculation for Multi-pass Single Welded Joint between a Plate and Penetrating Pipe," Modeling of Casting, Welding and Advanced Soldification Processes V; The Minerals, Metals and Materials Society, pp. 219-227, 1991.

[3] Y. Ueda und K. Nakacho, ,Simplifying Methods for Analysis of Transient and Residual Stresses and Deformations due to Multi-pass Welding," Transactions of Joining and Welding Research Institute, Osaka University, pp. 95-103, 31 März 1982.

[4] J. Hong, C.-L. Tsai und P. Dong, „Assessment of numerical procedures for residual stress analysis of multipass welds,“ Welding journal, Bd. 77, Nr. 9, pp. 372-382, 1998.

[5] M. P. Macherauch E., „Das $\sin ^{2} \psi$-Verfahren der röntgenografischen Spannungsmessung,“ Zeitschrift für angewandte Physik, Bd. 13, 1961.

[6] J. Dike, C. Cadden, R. Corderman, C. Schultz und M. McAninch, „Finite Element Modeling of Multipass GMA Welds in Steel Plates, " in Proceedings of the 4th International Conference on Trends in Welding Research, Tennessee, 1995.

[7] H. Serizawa, S. Nakamura, K. Kanbe, Y. Fujita, S. Asai und H. Murakawa, „Numerical analysis of deformation in multi-pass circumferential TIG welding with narrow gap, "Welding in the World, Nr. 57, pp. 615-623, 10 Mai 2013. 